\title{
Divergent thermal specialisation of two South African entomopathogenic nematodes
}

Matthew P Hill, Antoinette P Malan, John S Terblanche

Thermal physiology of entomopathogenic nematodes (EPN) is a critical aspect of field performance and fitness. Thermal limits for survival and activity, and the ability of these limits to adjust (i.e. show phenotypic flexibility) depending on recent thermal history, are generally poorly established, especially for non-model nematode species. Here we report the acute thermal limits for survival, and the thermal acclimation-related plasticity thereof for two key endemic South African EPN species. Results indicate Steinernema yirgalemense has greater high temperature tolerance, but poorer low temperature tolerance in comparison to Heterorhabditis zealandica, suggesting these two EPN species occupy divergent thermal niches to one another. Acclimation had both negative and positive effects on survival of both species, although the overall variation meant that many of these effects were non-significant. There was no indication of a consistent loss of plasticity with improved basal thermal tolerance for either species at upper lethal temperatures. At lower temperatures measured for $\mathrm{H}$. zealandica, the $5^{\circ} \mathrm{C}$ acclimation lowered survival until below $-12.5^{\circ} \mathrm{C}$, where after it increased survival. Such results indicate that the thermal niche breadth of EPN species can differ significantly depending on recent thermal conditions, and should be characterized across a broad range of species to understand the evolution of thermal limits to performance and survival in this group. 
3 Matthew P. Hill ${ }^{1}$, Antoinette P. Malan ${ }^{2} \&$ John S. Terblanche ${ }^{1}$

$4 \quad{ }^{1}$ DST-NRF Centre of Excellence for Invasion Biology, Department of Conservation Ecology and

5 Entomology, Faculty of AgriSciences, Stellenbosch University, Private Bag X1, Matieland 7602, South

6 Africa

$7 \quad{ }^{2}$ Department of Conservation Ecology and Entomology, Faculty of AgriSciences, Stellenbosch

8 University, Private Bag X1, Matieland 7602, South Africa

9 email: hillmp@sun.ac.za

10 Abstract

Thermal physiology of entomopathogenic nematodes (EPN) is a critical aspect of field performance and fitness. Thermal limits for survival and activity, and the ability of these limits to adjust (i.e. show phenotypic flexibility) depending on recent thermal history, are generally poorly established, especially for non-model nematode species. Here we report the acute thermal limits for survival, and the thermal acclimation-related plasticity thereof for two key endemic South African EPN species, Steinernema yirgalemense and Heterorhabditis zealandica. Results including $\mathrm{LT}_{50}$ indicate $S$. yirgalemense $\left(\mathrm{LT}_{50}=\right.$ $40.8 \pm 0.3^{\circ} \mathrm{C}$ ) has greater high temperature tolerance than $H$. zealandica $\left(\mathrm{LT}_{50}=36.7 \pm 0.2^{\circ} \mathrm{C}\right)$, but $S$. yirgalemense $\left(\mathrm{LT}_{50}=-2.4 \pm 0^{\circ} \mathrm{C}\right)$ has poorer low temperature tolerance in comparison to $\mathrm{H}$. zealandica $\left(\mathrm{LT}_{50}=-9.7 \pm 0.3^{\circ} \mathrm{C}\right)$, suggesting these two EPN species occupy divergent thermal niches to one another.

Acclimation had both negative and positive effects on temperature stress survival of both species, although the overall variation meant that many of these effects were non-significant. There was no indication of a consistent loss of plasticity with improved basal thermal tolerance for either species at upper lethal temperatures. At lower temperatures measured for $\mathrm{H}$. zealandica, the $5^{\circ} \mathrm{C}$ acclimation lowered survival until below $-12.5^{\circ} \mathrm{C}$, where after it increased survival. Such results indicate that the thermal niche breadth of EPN species can differ significantly depending on recent thermal conditions, and should be characterized across a broad range of species to understand the evolution of thermal limits to performance and survival in this group. 


\section{Introduction}

Temperature plays a key role in both the survival and activity of terrestrial invertebrates. Thermal tolerance may be characterized through traits such as thermal maxima and minima (absolute limits), processes or rates (e.g. development), as well as the optima thereof (e.g. temperatures for which growth rate and reproduction are maximised). Such basal thermal tolerance of terrestrial invertebrate species may also be adjusted through plastic responses induced through acclimation, hardening or acclimatization, allowing for phenotypic flexibility in the species relationship to temperature (Chown \& Terblanche, 2006; Angilletta, 2009). Plasticity may thus allow for environmental extremes to be buffered against, although sometimes this comes with a trade-off with basal thermal tolerance (Calosi et al., 2008; Nyamukondiwa et al., 2011). Information on both basal thermal tolerance and the plasticity thereof can be compared to give insight into hierarchical levels of, and the magnitude and direction of, variation that may exist between species and across different groups (e.g. Hoffmann et al., 2013; Faulkner et al., 2014), and thus constraints or trade-offs that may be significant for understanding adaptive evolution.

Entomopathogenic nematodes (EPNs) are soil inhabiting insect parasites that fall within two monogeneric families: Heterorhabditidae and Steinernematidae (Rhabditida) (Hunt, 2007). The families do not share a common ancestry, but have nonetheless developed a similar lifestyle (Blaxter et al., 1998). Heterorhabditids and steinernematids each have corresponding mutualistic bacteria in the genera Photorhabdus and Xenorhabdus, respectively. These bacteria are held within the nematode intestine and released once the infective juvenile (IJ) has penetrated the insect host through the natural openings (spiracles, mouth or anus) (Griffin et al., 2005). The bacteria suppress the host's immune system, typically killing the host within $24-48 \mathrm{~h}$, subsequently providing nutrition for the nematodes and their offspring (Gaugler et al., 1997; Griffin et al., 2005). The EPNs are then able to complete multiple (e.g. up to three) generations within the insect cadaver (depending on the size of the host) before releasing a new cohort of IJs to start a new cycle (Gaugler et al., 1997). This life history strategy has allowed for the development of different biocontrol programmes using soil and aerial application of the IJs on agricultural pest insects (Lacey \& Georgis, 2012).

There appears to be a wide range of responses to environmental stress exhibited across EPN species and strains, including variation in desiccation tolerance and hypoxia tolerance, and freeze tolerance (Morton \& García-del-Pino, 2009; Salame et al., 2012; Shapiro-Ilan et al., 2014). Some of the variation exhibited for cold tolerance is most likely attributed to different adaptive strategies including cryoprotective dehydration, anhydrobiosis and freeze avoidance or tolerance strategies (Wharton, 2011), although the mechanisms underlying cold tolerance responses are typically the primary focus of investigation (e.g. Ali 
\& Wharton, 2014). While EPNs are able to withstand adverse environmental conditions inside their host cadavers, the IJ stage is required to seek out new hosts and thus may be particularly vulnerable to environmental variability in this life-stage (Brown \& Gaughler, 1997). Much of the work looking at thermal performance of EPNs has focused on cold tolerance and how this relates to long-term cold storage solutions, or overwinter survival of free-living nematodes in polar environments (Perry and Wharton, 2011), although there have been assessments of heat tolerance in EPNs (e.g Shaprio et al., 1996; Jagdale \& Gordon, 1998).

In addition to variation in basal thermal tolerance, acclimation-related adjustments in tolerance may be substantial in nematodes. For example, higher temperatures experienced during propagation increase upper thermal limits, while diminishing lower thermal ones (Grewal et al. 1996; Shaprio et al., 1996; Jagdale \& Gordon, 1998). Further, short term exposure to lower temperatures prior to freezing has been shown to enhance freezing survival (Ali \& Wharton, 2012). Previous EPN cold tolerance work has included findings that Heterorhabditis bacteriophora Poinar, 1976 and Steinernema feltiae (Filipjev, 1934) Wouts, Mráček, Gerdin \& Bedding, 1982 (Rhabditida: Heterorhabditidae) have demonstrated an increase in freezing tolerance after acclimation to temperatures below their propogation temperature (Brown \& Gaugler, 1996; Ali \& Wharton, 2012). Thus, testing thermal tolerances and associated plasticity or physiological adjustments in response to propagation or short-term temperature treatments to estimate thermal niche breadth across EPN species should help identify potential trade-offs between basal and acute responses. From an evolutionary perspective, understanding whether specialization to a particular environment has evolved at the expense of poorer performance in another environment is a significant avenue for forecasting and managing climate change responses over longer timescales (see discussion in Angilletta, 2009; Gilchrist, 1995).

Heterorhabditis zealandica and Steinernema yirgalemense Tesfamariam, Gozel, Gaugler and Adams, 2005 have demonstrated high virulence against a range of pest insect species in South Africa, including the mealybugs, Planococcus ficus (Signoret) and P. citri (Risso) (Hemiptera: Pseudococcidae) (Van Niekerk \& Malan, 2012; Le Vieux \& Malan, 2013) and tortricid moths (De Waal et al., 2011; Malan et al., 2011). Heterorhabditis zealandica was originally described in New Zealand, and though it is not a common species, it has been reported from the USA, Lithuania, Russia, Australia and South Africa (see Malan et al., 2006). Steinernema yirgalemense was first described from Ethiopia (Nguyen et al., 2004), and is highly prevalent there (Mekete et al., 2005), and also found in Kenya (Mekete et al., 2005) with only one isolate from South Africa (Malan et al., 2011). Importantly, these two species have demonstrated higher efficacy in host mortality than other EPN species and thus provide two potential candidates for ongoing pest management programmes (Van Niekerk \& Malan, 2012). There are however, 
important differences between the species that require further investigation. Steinernema yirgalemense is two times more tolerant to low levels of free water than H. zealandica and has been demonstrated to detect and infect $P$. citri hosts quicker (Van Niekerk \& Malan, 2012). Heterorhabditis zealandica and $S$. yirgalemense may therefore have contrasting thermal tolerance profiles.

In this paper we aim to characterise and compare the lethal upper and lower temperatures for $H$. zealandica and S. yirgalemense by using an accurately controlled thermal stage. We extend on estimating the thermal niche breadth and examine whether short term induced thermal acclimation is able to alter basal thermal resistance in these EPN species and discuss potential evolutionary trade-offs.

\section{Materials \& Methods}

\section{Codling moth cultures}

Recently the virulence of $H$. zealandica and $S$. yirgalemense on codling moth Cydia pomonella L. (Lepidoptera: Tortricidae) was demonstrated to result in above $90 \%$ mortality and rapid EPN development time, thus providing a suitable in vivo host for these EPN species (De Waal et al. 2011). We obtained C. pomonella eggs and diet from Entomon Technologies (Pty) Ltd, Stellenbosch, Western Cape province, South Africa. The codling moth diet consists of agar, carrageenan, yeast, wheat germ, brown bread flower, ascorbic acid, benzoic acid, nipagin and formalin (Stenekamp, 2011). After hatching, $C$. pomonella larvae were reared on this diet under diapausing conditions in temperature controlled cabinets (10:14h L:D photoperiod, $25^{\circ} \mathrm{C}, 60 \% \mathrm{RH}$ ).

\section{Nematode cultures}

We used IJ of H. zealandica and S. yirgalemense (Malan et al., 2006; 2011) from Stellenbosch University stocks (isolates SF41 and 157-C respectively). Both of these species were originally collected within South Africa (SF41 from Patensie, Eastern Cape and 157-C from Friedenheim, Mpumalanga [Malan et al. 2006; 2011]). Fifth instar C. pomonella larvae were used as host for culturing IJ of the two EPNs species. Development period was held at $25^{\circ} \mathrm{C}$ and lasted for around 10 days. Emerging IJ were collected over a 3 day period using modified White traps (White, 1927) and stored at $14^{\circ} \mathrm{C}$ in distilled water, in horizontally placed, vented culture flasks, until use. We quantified the IJs to 100 individuals per $50 \mu 1$ prior to assays (Navon \& Ascher, 2000). The experiments were repeated with fresh batches of recycled nematodes, in an attempt to control for any cohort effects (see Supplementary Material 1).

\section{Experimental setup}


124 All temperature survival assays were performed using the stage design of Hill et al. (2013). This was

125 originally used to measure critical thermal limits of mites, but was suited to temperature assays of EPNs

126 due to being an open-well design. Briefly, this stage is an aluminium double-jacketed block (100 mm *

$127100 \mathrm{~mm} * 10 \mathrm{~mm}$ ) with 19 wells (5 mm diameter). The wells are arranged in a circle and the middle well

128 was used as a control, with a thermocouple (type K) secured in place. A perspex lid covers this stage so

129 that each well is kept sealed during experimentation. Samples can be easily pipetted to and from each well

130 and thoroughly rinsed between replicates to prevent contamination.

131 This stage was connected to a thermoregulator controller and waterbath (Huber cc410wl) filled with

132 either ethanol for low temperature assays or 50:50 propylene glycol:water for high temperature assays.

133 The temperature controlled fluid was pumped through channels in this block and allows for accurate

134 temperature control, and verified independently.

135 Upper Lethal Temperatures

136 As the number of nematodes taken in each pipette draw was quite variable, we took $100 \mu 1$ of each

137 quantified sample to ensure a minimum number of individuals $(n>50)$ and then nematode samples were

138 transferred into individual wells in the thermal stage. We used two replicates of each species for each

139 different temperature assay.

140 The initial temperature was set and held for $5 \mathrm{~min}$ at $25^{\circ} \mathrm{C}$ before being quickly ramped up at $0.5^{\circ} \mathrm{C} \min ^{-1}$

141 to the set high temperature (set at: $35,37,39,41,43^{\circ} \mathrm{C}$ ). After being held at this temperature for $60 \mathrm{~min}$,

142 the temperature was ramped back down to $25^{\circ} \mathrm{C}$ at $0.5^{\circ} \mathrm{C} \mathrm{min}{ }^{-1}$. While this rate is different from

143 temperature change experienced in the field (for the temperate regions of collection for these EPN

144 species, e.g. Nyamukondiwa \& Terblanche, 2010), it still allows for physiological differences between

145 species to be contrasted, and has been employed for characterising nematode tolerances elsewhere (e.g.

146 Ali \& Wharton, 2013; 2014), thus maximising possibility of comparison between studies. While this was

147 still relatively quick, ramping assays are likely to be more ecologically relevant than static assays,

148 especially in capturing elements of the daily thermal cycles and whether these may pose survival limits

149 (Terblanche et al., 2011).

150 Temperature was recorded every second during the run using a PicoLog TC-08 USB datalogger and

151 PicoLog software. We took the observed temperature to be the average temperature for the period

152 between 3000 and 4000 seconds as this allowed for stabilization of the waterbath away from ramping

153 temperature times. 
154 Following assays each sample was drawn from the well and placed in a $500 \mu 1$ Eppendorf tube, together

155 with $0.025 \mathrm{~g} / 100 \mathrm{~mL}$ Meldola's blue dye to stain dead cells (Ogiga \& Estey, 1974). Nematode survival

156 was scored 24 hours post assay with the aid of a dissection microscope (Leica MZ7s). By using a

157 combination of dye penetration, mechanical stimulus (probing with dissection needle) and nematode

158 shape it was possible to record mortality with a high level of accuracy.

159

160

161

162

163

164

165

166

167

168

169

170

171

172

173

174

175

176

177

178

179

180

181

182

183

184

\section{Lower Lethal Temperature}

We conducted these assays as we did for upper lethal temperatures, but with a few changes. Experiments were started at $5^{\circ} \mathrm{C}$, held at this temperature for $5 \mathrm{~min}$ and then ramped down at $0.5^{\circ} \mathrm{C} \mathrm{min}^{-1}$ to the different set temperatures (set at: $-5,-6,-7,-8,-9,-10,-11,-12,-13,-14,-15^{\circ} \mathrm{C}$ ). While other studies have required seeded freezing of samples (e.g. Ali \& Wharton 2014; Shapiro-Ilan et al., 2014), our stage design allows for freezing to occur passively, instead of supercooling taking place. Freezing was observed to occur in the wells through detection of an exothermic release on the temperature recordings. The temperature was then raised back up at the same rate to $5^{\circ} \mathrm{C}$ before the nematodes taken to be held at $25^{\circ} \mathrm{C}$ for 24 hours prior to scoring survival. Observed temperature was calculated as the average between 1000 and 2000 seconds from recordings of the thermocouple in the middle well. Survival was scored as for the upper lethal temperature assays.

\section{Acclimation}

To investigate the effects of induced acclimation on EPNs we placed samples of both species into different constant temperature incubators (and cold rooms) and held for 24 hours prior to experimentation. In previous studies examining thermal tolerance in EPN species, it was found that periods of time ranging from a few hours through to two days was sufficient to induce an acute effect of acclimation, hence we chose a period of 24 hours (see discussion). We held samples at 5, 20 and $30^{\circ} \mathrm{C}$ and included two replicates of each acclimation treatment with two control temperature samples $\left(25^{\circ} \mathrm{C}\right)$ for both species. For the acclimation treatments, we selected a number of temperatures appropriate to each species based on results from upper lethal temperature (ULT) and lower lethal temperature (LLT) experiments (H. zealandica: LLT: $-5,-6,-7,-13,-14,-15^{\circ} \mathrm{C}$, ULT: $35,37,39^{\circ} \mathrm{C} ;$ S. yirgalemense: LLT: $\left.5,-6^{\circ} \mathrm{C}, \mathrm{ULT}: 35,37,39,41,43^{\circ} \mathrm{C}\right)$. We also added the control replicate data from these acclimation experiments back to our ULT and LLT datasets to increase their sample size.

\section{Statistical analysis}

All statistical analyses were performed in R (version 3.1.2; R core team, 2014). For the upper and lower lethal temperature experiments, without acclimation treatments, we modelled percentage survival as a 
function of observed temperature for both species separately using generalised linear models (glmfunction) with a binomial distribution and a logit link function. We tested for over-dispersion using the dispmod (version 1.1) package and then rescaled deviance to 1 when necessary. We then calculated $\mathrm{LT}_{10}, \mathrm{LT}_{50}$ and $\mathrm{LT}_{90}$ temperature profiles for each species using the dose.p function in the MASS package.

For the acclimation experiments we again considered each species separately and performed generalised linear models using binomial distributions and logit link function. In this case we used set temperature rather than observed temperature so that we could examine acclimation between cohorts, and then added acclimation treatment as an additional effect and an interaction term between acclimation and set temperature. Temperature and acclimation treatments were used as categorical variables and then Wald's $\chi^{2}$ test in the "arm" package was used to test the significance of these predictors.

\section{Results}

Heterorhabditis zealandica and S. yirgalemense displayed contrasting lethal temperature responses (Fig. 1). Overall, $S$. yirgalemense displayed greater survival at higher temperatures than $H$. zealandica (simplified Wald $z=-4.48, p<0.001$ ) (Table 1). For lower lethal temperatures, this pattern was reversed: H. zealandica had higher survival at low temperatures than S. yirgalemense (simplified Wald $z=7.99, p$ $<0.001$ ) (Table 1). These differences are also reflected in thelethal temperature values predicted by the generalized linear models (Table 2). The predicted curves for survival of the two species show distinct and contrasting responses to upper and lower lethal temperatures (Fig. 1).

For both species, acclimation of thermal limits in both species resulted in both negative and positive responses to experimental temperatures as seen in both lower and higher survival limits at different temperatures (Fig. 2). There was considerable variation between acclimation treatments, and the overall effect of acclimation and the interaction with temperature was non-significant (Table 3). For $H$. zealandica ULT performance was increased by the $30^{\circ} \mathrm{C}$ acclimation treatment, especially at the $39^{\circ} \mathrm{C}$ test temperature, although this was not significant. There was no increase in survival at $41^{\circ} \mathrm{C}$ test temperatures from any of the acclimation treatments. For $S$. yirgalemense, the $30^{\circ} \mathrm{C}$ acclimation increased survival at $41^{\circ} \mathrm{C}$ and even slightly at $43^{\circ} \mathrm{C}$, although this again was not significant.

For lower lethal temperatures, $\mathrm{H}$. zealandica individuals acclimated at $5^{\circ} \mathrm{C}$ have decreased performance until the experimental temperatures dropped below $-12.5^{\circ} \mathrm{C}$, when this acclimation treatment gave increased survival down to $-15^{\circ} \mathrm{C}$ (significantly so from 20 and $30^{\circ} \mathrm{C}$ acclimations; $\chi^{2}{ }_{1}=6.0, p=0.014$ and $\chi^{2}{ }_{1}=6.4, p=0.011$, respectively). Acclimations treatments of 5 and $30^{\circ} \mathrm{C}$ were significantly different from one another for $H$. zealandica $\left(\chi^{2}{ }_{1}=6.2, p=0.013\right)$ and this was driven by the differences at -7 and 
$-13^{\circ} \mathrm{C}\left(\chi^{2}{ }_{1}=8.3, p=0.004\right.$ and $\chi^{2}{ }_{1}=6.2, p=0.011$, respectively $)$, displaying both decreased and increased survival, respectively. This pattern was also observed for the 5 and $20^{\circ} \mathrm{C}$ acclimation treatments, at the $-7^{\circ} \mathrm{C}$ test temperature the $5^{\circ} \mathrm{C}$ acclimation treatment displayed significantly decreased survival from the 20 and $\left(\chi^{2}{ }_{1}=5.0, p=0.025\right)$ and then atthe $-13^{\circ} \mathrm{C}$ test temperature, the $5^{\circ} \mathrm{C}$ acclimation treatment again gave significantly increased survival over the $20^{\circ} \mathrm{C}$ treatment $\left(\chi^{2}{ }_{1}=6.0, p=\right.$ 0.014) While there was insufficient data to test for acclimation and LLT for S. yirgalemense, there appears to be a well-defined threshold of survival around $-5^{\circ} \mathrm{C}$, with temperatures below this resulting in complete mortality and acclimation treatments unable to elicit a shift this threshold.

In the replication of acclimation experiments we observed some significant differences between experiments (Supplementary Material 1). Particularly for H. zealandica ULTs, the second cohort displayed significantly higher survival at $37^{\circ} \mathrm{C}\left(\chi^{2}{ }_{1}=25.6, p=<0.001\right.$; Supplementary Material 1). Likewise, at $41^{\circ} \mathrm{C}$ for $S$. yirgalemense, the first cohort was significantly different from the second $\left(\chi^{2}{ }_{1}=\right.$ 5.3, $p=<0.021)$ and the acclimation response was also more evident in the first experiments (Supplementary Material 1). For $H$. zealandica LLTs the cohorts were significantly different at $-5^{\circ} \mathrm{C}\left(\chi^{2}{ }_{1}=\right.$ 9.4, $p=0.002),-7^{\circ} \mathrm{C}\left(\chi^{2}{ }_{1}=4.3, p=0.39\right)$ and $-13^{\circ} \mathrm{C}\left(\chi^{2}{ }_{1}=10.9, p=<0.001\right)$. While these differences in response between the experimental cohorts were significant, the pattern of interaction between acclimation and temperature was largely preserved within both cohorts and on the combined data of these experiments (Supplementary Material 1).

\section{Discussion}

Our results here demonstrate contrasting thermal tolerance profiles for two EPN species and support findings that thermal tolerance varies widely across different EPN species (e.g. Morton \& García-delPino, 2009; Shapiro-Ilan et al., 2014). The two contrasting thermal tolerance curves were obtained on isolates that have been kept under the same laboratory conditions for many generations (Malan et al., 2006 ; 2011) and thus the differences observed here are likely to be due to fixed genetic differences rather than recent environmental influences (i.e. acclimatization). However, inadvertent directional selection during laboratory propagation may have influenced the estimates of thermal tolerance for these species (Grewal et al., 1996). The two species are also from separate monogeneric families within the Rhabditida and have thus have had disparate evolutionary histories. It has been proposed that Heterorhabditis species are endemic to warmer climates, whilst Steinernema species more common in temperate regions (see Grewal et al., 1994), however our estimates of tolerances from the laboratory-propagated lines did not reflect this. Further studies on field collected EPNs are therefore required to examine if patterns of 
247 thermal resistance are consistently different between the two families in line with biogeographical

248 hypotheses.

249 While the overall effects of acclimation were complex, both species exhibited some improved survival 250 after being acclimated at $30^{\circ} \mathrm{C}$ for high temperature assays, and consequently, do not support evidence of 251 a direct trade-off between plastic and basal ULT. Other EPN studies have identified that acute acclimation 252 provides improved thermal performance for some species (e.g. S. carpocase and S. feltiae; Jagdale \& 253 Grewal, 2003) but not others (e.g. S. ribrave; Jagdale \& Grewal, 2003), indicating that trade-offs and 254 mechanisms may exist in EPNs. While there is currently little information on trade offs between basal and 255 induced thermal limits in EPN systems, previous studies of Drosophila species have identified trade-offs 256 between basal low-temperature tolerance and acute low-temperature plasticity, but at high temperatures 257 increased basal tolerance was accompanied by increased plasticity (Nyamukondiwa et al., 2011).

258 However, thermal acclimation may provide other costs and benefits to performance, such as increased 259 resistance to desiccation or reduced fecundity or longevity, which were not the focus of investigation here 260 (Kleynhans et al., 2014; Terblanche, 2014). While our period of 24 hours for acclimation may be 261 considered quite short, short-term acute responses to temperature regimes have been documented in 262 EPNs. For instance, a few hours at $35^{\circ} \mathrm{C}$ has improved both $H$. bacteriophora survival and infectivity at $26340^{\circ} \mathrm{C}$ (Selvan et al., 1996), one to two days acclimation has improved thermal tolerance in S. carpocase 264 and S. feltiae (Jagdale \& Grewal, 2003), and an overnight freezing treatment prior to LLT characterization 265 has demonstrated improved survival in S. feltiae (Ali \& Wharton, 2013). As we were examining 266 responses of previously uncharacterized species, we selected a time frame for acclimation that should not 267 overtly stress the organism prior to treatment, but be sufficient to elicit a response. The onset and reversal 268 of acclimation responses are not well understood even in more well-examined groups such as insects 269 (Weldon et al., 2011), thus future tests should explore these responses further in EPNs the range of 270 conditions that elicit acclimation responses and the persistence thereof.

271 Unlike most EPN species, which are freeze tolerant, H. zealandica has been shown to exhibit a freeze 272 avoidance strategy, enabled through a protective sheath (Wharton \& Surrey, 1994), and cold acclimation 273 has been found to decrease freezing survival in H. zealandica (Surrey, 1996). We also found evidence for 274 acclimation to decrease survival at some low temperatures on the isolate used: however, at the lowest 275 temperatures the $5^{\circ} \mathrm{C}$ acclimation treatment actually increased survival. In addition to the presence or 276 absence of a protective sheath which greatly influences $H$. zealandica survival at low temperatures 277 (Wharton \& Surrey, 1994), species that undergo anhydrobiosis require that dehydration is actually 278 possible through differences in water vapour pressure between the surrounding ice and bodily fluids 279 (Holmstrup et al. 2002). Anhydrobiosis has evolved as a freeze avoidance strategy in addition to 
280

281

282

283

284

285

286

287

288

289

290

291

292

293

294

295

296

297

298

299

300

301

302

303

304

305

306

307

308

309

310

311

312

supercooling in many soil invertebrates (Holmstrup et al. 2002), and as the IJs were in an aqueous solution, such protective dehydration could probably not occur in the liquid medium we used for our assays, which may have influenced survival results for low temperatures tested here. Variation in results may also arise from differences in how acclimation and freezing are implemented into experiments, as substantial variation in results of acclimation experiments appear to be common for EPNs (Ali \& Wharton, 2013). Differences from previous studies may also be related to our thermal stage design and reliance on freezing to occur spontaneously, as opposed to samples being seeded (inoculated) with ice crystals in other studies (e.g. Ali \& Wharton, 2013). Ali \& Wharton (2013) also suggest that the duration for which IJs are exposed to the temperature of ice nucleation has implications on survival of freezetolerant species such as $S$. feltiae. Experimental setup and freeze avoidance strategies are thus both likely to introduce further variation and have implications for species comparisons, especially for species where cryoprotective dehydration needs to occur (Brown \& Gaugler, 1998; Ali \& Wharton, 2013). This is something that should be considered in broader comparisons of cold tolerance across EPN species.

The differences between the cohorts in the replication of our acclimation experiments could be due to a number of factors. Given that nematodes are propagated under controlled conditions, the most likely sources of variation are perhaps differences in age of the nematodes on a given experimental day and/or variation in host health and nutritional content, e.g. lipid composition (Grunder \& Jurg, 2005) which may have a marked effect on plasticity and basal tolerance, especially if linked to IJ ability to synthesise heat shock proteins and cryoprotectants such as trehalose and glycerol (Grewal \& Jagdale, 2002; Jagdale et al., 2005). Observer bias is also unlikely as a consistent directional influence since observers were well trained and produced inconsistent differences/similarities in direction of effects on the same treatment (see e.g. discussions in Terblanche et al., 2011; Castaneda et al., 2012; Blackburn et al., 2014). The cultures are maintained in a highly stable environment so environmental differences in terms of temperature and humidity are unlikely. And while we only conducted experiments on IJs that were less than 2 weeks old, the age of the IJ EPNs prior to experiment should be further investigated. We attempted to use all EPNs at the same time, but our experiment setup is limited to one stage and thus we are required to run our experiments in series, spanning over two weeks to complete them all. Time post emergence may be an important factor in thermal stress resistance.

Thermal tolerance of EPN species plays a key role in components of its life history, including mobility of the IJ, infection, development and reproduction (Grewal et al., 1994; Morton \& García-del-Pino, 2009; Salame et al., 2012; Shapiro-Ilan et al., 2014). These results encourage for more EPN species to be characterized using these methods to better understand thermal tolerance in these nematodes and how this relates to biogeographical patterns as well as the evolution of thermal resistance in this group. 
313

314

315

316

317

318

319

320

321

322

323

324

325

326

327

328

329

330

331

332

333

334

335

336

337

338

339

\section{Acknowledgements}

The authors thank Elizabeth Louw for assisting with experiments. Md Habibullah Bahar and C. Jaco Klok provided useful comments during review of this manuscript.

\section{References}

Ali, F., \& Wharton, D. A. (2013). Cold tolerance abilities of two entomopathogenic nematodes, Steinernema feltiae and Heterorhabditis bacteriophora. Cryobiology, 66(1), 24-29.

Ali, F., \& Wharton, D. A. (2014). Intracellular freezing in the infective juveniles of Steinernema feltiae: an entomopathogenic nematode. PloS one, 9(4), e94179.

Angilletta, M. J. (2009). Thermal adaptation: a theoretical and empirical synthesis. Oxford University Press.

Blackburn, S., van Heerwaarden, B., Kellermann, V., \& Sgrò, C. M. (2014). Evolutionary capacity of upper thermal limits: beyond single trait assessments. The Journal of Experimental Biology, 217(11), 1918-1924.

Brown, I. M., \& Gaugler, R. (1996). Cold tolerance of steinernematid and heterorhabditid nematodes. Journal of thermal biology, 21(2), 115-121.

Brown, I. M., \& Gaugler, R. (1998). Survival of steinernematid nematodes exposed to freezing. Journal of thermal biology, 23(2), 75-80.

Calosi, P., Bilton, D. T., \& Spicer, J. I. (2008). Thermal tolerance, acclimatory capacity and vulnerability to global climate change. Biology Letters, 4(1), 99-102.

Castaneda, L. E., Calabria, G., Betancourt, L. A., Rezende, E. L., \& Santos, M. (2012). Measurement error in heat tolerance assays. Journal of Thermal Biology, 37(6), 432-437.

Chown, S. L., \& Terblanche, J. S. (2006). Physiological diversity in insects: ecological and evolutionary contexts. Advances in insect physiology, 33, 50-152.

De Waal, J. Y., Malan, A. P., \& Addison, M. F. (2011). Efficacy of entomopathogenic nematodes (Rhabditida: Heterorhabditidae and Steinernematidae) against codling moth, Cydia pomonella (Lepidoptera: Tortricidae) in temperate regions. Biocontrol Science and Technology, 21(10), 1161-1176. 
340 Faulkner, K. T., Clusella-Trullas, S., Peck, L. S., \& Chown, S. L. (2014). Lack of coherence in the

341 warming responses of marine crustaceans. Functional Ecology, 28(4), 895-903.

342 Gaugler, R., Lewis, E., \& Stuart, R. J. (1997). Ecology in the service of biological control: the case of 343 entomopathogenic nematodes. Oecologia,109(4), 483-489.

344 Gilchrist, G. W. (1995). Specialists and generalists in changing environments. I. Fitness landscapes of 345 thermal sensitivity. American Naturalist, 252-270.

346 Grewal, P. S., \& Jagdale, G. B. (2002). Enhanced trehalose accumulation and desiccation survival of 347 entomopathogenic nematodes through cold preacclimation. Biocontrol Science and Technology, 12(5), 348 533-545.

349 Grewal, P. S., Selvan, S., \& Gaugler, R. (1994). Thermal adaptation of entomopathogenic nematodes:

350 niche breadth for infection, establishment, and reproduction. Journal of Thermal Biology, 19(4), 245-253.

351 Grewal, P. S., Gaugler, R., \& Shupe, C. (1996). Rapid changes in thermal sensitivity of

352 entomopathogenic nematodes in response to selection at temperature extremes. Journal of invertebrate 353 pathology, 68(1), 65-73.

354 Griffin, C.T., Boemare, N.E. \& Lewis, E.E., (2005). Biology and behaviour. In: Grewal, P.S., Ehlers, R.355 U. \& Shapiro-Ilan, D.I. (eds). Nematodes as biocontrol agents. CABI Publishing, Wallingford, UK. pp. $356 \quad 47-75$.

357 Grunder, J.M. \& Jung, K. (2005). Quality control of entomopathogenic nematodes: proceedings of 358 workshops and meetings held in Merelbeke (Belgium), Maynooth (Ireland), Vienna (Austria) and 359 Wageningen (the Netherlands), 1999-2001. Wädeswil, Switzerland.

360 Hill, M. P., Chown, S. L., \& Hoffmann, A. A. (2013). A predicted niche shift corresponds with increased 361 thermal resistance in an invasive mite, Halotydeus destructor. Global Ecology and Biogeography, 22(8), $362942-951$.

363 Hoffmann, A. A., Chown, S. L., \& Clusella-Trullas, S. (2013). Upper thermal limits in terrestrial 364 ectotherms: how constrained are they?. Functional Ecology,27(4), 934-949.

365 Holmstrup, M., Bayley, M., \& Ramløv, H. (2002). Supercool or dehydrate? An experimental analysis of 366 overwintering strategies in small permeable arctic invertebrates. Proceedings of the National Academy of 367 Sciences, 99(8), 5716-5720. 
368 Hunt, D.J. (2007). Overview of taxonomy and systematics. In: Nguyen, K,B. \& Hunt, D.J. (eds).

369 Entomopathogenic nematodes: Systematics, phylogeny and bacterial symbionts. Brill Leiden-Boston, The

370 Netherlands. pp. 27-57.

371 Jagdale, G. B., \& Gordon, R. (1998). Effect of propagation temperatures on temperature tolerances of 372 entomopathogenic nematodes. Fundamental and applied nematology, 21(2), 177-184.

373 Jagdale, G. B., \& Grewal, P. S. (2003). Acclimation of entomopathogenic nematodes to novel

374 temperatures: trehalose accumulation and the acquisition of thermotolerance. International Journal for

375 Parasitology, 33(2), 145-152.

376 Jagdale, G. B., Grewal, P. S., \& Salminen, S. O. (2005). Both heat-shock and cold-shock influence

377 trehalose metabolism in an entomopathogenic nematode. Journal of Parasitology, 91(5), 988-994.

378 Kleynhans, E., Mitchell, K. A., Conlong, D. E., \& Terblanche, J. S. (2014). Evolved variation in cold 379 tolerance among populations of Eldana saccharina (Lepidoptera: Pyralidae) in South Africa. Journal of 380 Evolutionary Biology, 27(6), 1149-1159.

381 Lacey, L.A., \& Georgis, R. (2012). Entomopathogenic nematodes for control of insect pest above and

382 below ground with comments on commercial production. Journal of Nematology 44 (2), 218-225.

383 Le Vieux, P. D., \& Malan, A. P. (2013). The potential use of entomopathogenic nematodes to control 384 Planococcus ficus (Signoret)(Hemiptera: Pseudococcidae). South African Journal of Enolology and 385 Viticulture 34 (1), 296-306.

386 Malan, A. P., Nguyen, K. B., \& Addison, M. F. (2006). Entomopathogenic nematodes (Steinernematidae 387 and Heterorhabditidae) from the southwestern parts of South Africa. African Plant Protection, 12, 65-69.

388 Malan, A. P., Knoetze, R., \& Moore, S. D. (2011). Isolation and identification of entomopathogenic 389 nematodes from citrus orchards in South Africa and their biocontrol potential against false codling moth. 390 Journal of invertebrate pathology, 108(2), 115-125.

391 Mekéte, T., Gaugler, R., Nguyen, K. B., Mandefro, W., \& Tessera, M. (2005). Biogeography of 392 entomopathogenic nematodes in Ethiopia. Nematropica, 35(1), 31-36.

393 Morton, A., \& García-del-Pino, F. (2009). Ecological characterization of entomopathogenic nematodes 394 isolated in stone fruit orchard soils of Mediterranean areas. Journal of Invertebrate Pathology, 102(3), 395 203-213. 
396 Navon, A., \& Ascher, K. R. S. (Eds.). (2000). Bioassays of entomopathogenic microbes and nematodes. 397 Cabi.

398 Nyamukondiwa, C., \& Terblanche, J. S. (2010). Within generation variation of critical thermal limits in 399 adult Mediterranean and Natal fruit flies Ceratitis capitata and Ceratitis rosa: thermal history affects 400 short-term responses to temperature. Physiological Entomology, 35(3), 255-264.

401 Nyamukondiwa, C., Terblanche, J. S., Marshall, K. E., \& Sinclair, B. J. (2011). Basal cold but not heat 402 tolerance constrains plasticity among Drosophila species (Diptera: Drosophilidae). Journal of 403 evolutionary biology, 24(9), 1927-1938.

404 Nguyen, K. B., Tesfamariam, M., Gozel, U., Gaugler, R., \& Adams, B. J. (2004). Steinernema

405 yirgalemense n. sp. (Rhabditida: Steinernematidae) from Ethiopia. Nematology, 6(6), 839-856.

406 Ogiga, I. R., \& Estey, R. H. (1974). The use of Meldola Blue and Nile Blue A, for distinguishing dead 407 from living nematodes. Nematologica, 20(3), 271-276.

408 Perry, R. N., \& Wharton, D. A. (Eds.). (2011). Molecular and physiological basis of nematode survival. 409 CABI.

410 R Core Team (2014). R: A language and environment for statistical computing. R Foundation for 411 Statistical Computing, Vienna, Austria. URL http://www.R-project.org/.

412 Salame, L., Glazer, I., Miqaia, N., \& Chkhubianishvili, T. (2010). Characterization of populations of 413 entomopathogenic nematodes isolated at diverse sites across Israel. Phytoparasitica, 38(1), 39-52.

414 Selvan, S., Grewal, P. S., Leustek, T., \& Gaugler, R. (1996). Heat shock enhances thermotolerance of 415 infective juvenile insect-parasitic nematodes Heterorhabditis bacteriophora (Rhabditida:

416 Heterorhabditidae). Experientia, 52(7), 727-730.

417 Shapiro, D. I., Glazer, I., \& Segal, D. (1996). Trait stability and fitness of the heat tolerant 418 entomopathogenic nematode Heterorhabditis bacteriophora IS5 strain. Biological Control, 6(2), 238-244.

419 Shapiro-Ilan, D. I., Brown, I., \& Lewis, E. E. (2014). Freezing and desiccation tolerance in 420 entomopathogenic nematodes: Diversity and correlation of traits. Journal of nematology, 46(1), 27-34.

421 Stenekamp, D. (2011). Optimization of a mass-rearing system to produce codling moth, Cydia pomonella, 422 for a Sterile Insect Release programme in South Africa. PhD dissertation, Faculty of AgriSciences, 423 Stellenbosch University, Stellenbosch, $125 \mathrm{pp}$. 
424 Surrey, M. R. (1996). Effect of rearing method and cool temperature acclimation on the cold tolerance of

425 Heterorhabditis zealandica infective juveniles (Nematoda: Heterorhabditidae). CryoLetters, 17, 313-320.

426 Terblanche, J. S. (2014). Physiological performance of field-released insects.Current Opinion in Insect

427 Science, 4, 60-66.

428 Terblanche, J. S., Hoffmann, A. A., Mitchell, K. A., Rako, L., le Roux, P. C., \& Chown, S. L. (2011).

429 Ecologically relevant measures of tolerance to potentially lethal temperatures. The Journal of

430 experimental biology, 214(22), 3713-3725.

431 Van Niekerk, S., \& Malan, A. P. (2012). Potential of South African entomopathogenic nematodes

432 (Heterorhabditidae and Steinernematidae) for control of the citrus mealybug, Planococcus citri

433 (Pseudococcidae). Journal of Invertebrate Pathology, 111(2), 166-174.

434 Weldon, C. W., Terblanche, J. S., \& Chown, S. L. (2011). Time-course for attainment and reversal of 435 acclimation to constant temperature in two Ceratitis species. Journal of Thermal Biology, 36(8), 479-485.

436 Wharton, D. A. (2011). Cold tolerance. Molecular and physiological basis of nematode survival. CABI

437 Publishing, Wallingford, 182-204.

438 Wharton, D. A., \& Surrey, M. R. (1994). Cold tolerance mechanisms of the infective larvae of the insect 439 parasitic nematode, Heterorhabditis zealandica Poinar. CryoLetters, 15, 353-360.

440 White, G.F. (1927) A method for obtaining infective nematode larvae from cultures. Science, 66, 302441303. 
Figure $\mathbf{1}_{\text {(on next page) }}$

Thermal performance curves for two entomopathogenic nematodes.

(a) Lower lethal temperatures (LLTs) as a function of percentage survival(0-1). Curves $\mathrm{glm}$ logit model fits. Green is Heterorhabditis zealandica, orange is Steinernema yirgalemense. (b) Upper lethal temperatures (ULTs) as a function of percentage survival(/10). Curves represent glm logit model fits. Green is Heterorhabditis zealandica, orange is Steinernema yirgalemense. See Table 1 for model summaries. 
Figure 2 (on next page)

Acclimation and lethal thermal tolerances for two species of entomopathogenic nematodes, Heterorhabditis zealandica and Steinernema yirgalemense.

Data represents both batches of experiments pooled together. Error bars reflect \pm 1 standard error, Survival measured between 0 (complete mortality) and 1 (complete survival). (a) Upper lethal temperatures and acclimation for Heterorhabditis zealandica. (b) Upper lethal temperatures and acclimation for Steinernema yirgalemense (c) Lower lethal temperatures and acclimation for Heterorhabditis zealandica. (d) Lower lethal temperatures and acclimation for Steinernema yirgalemense. 
(a)
PeerjJ Reviewing

H. zealandica Û́f Rev

ba)nuscrip

S. yirgalemense ULT

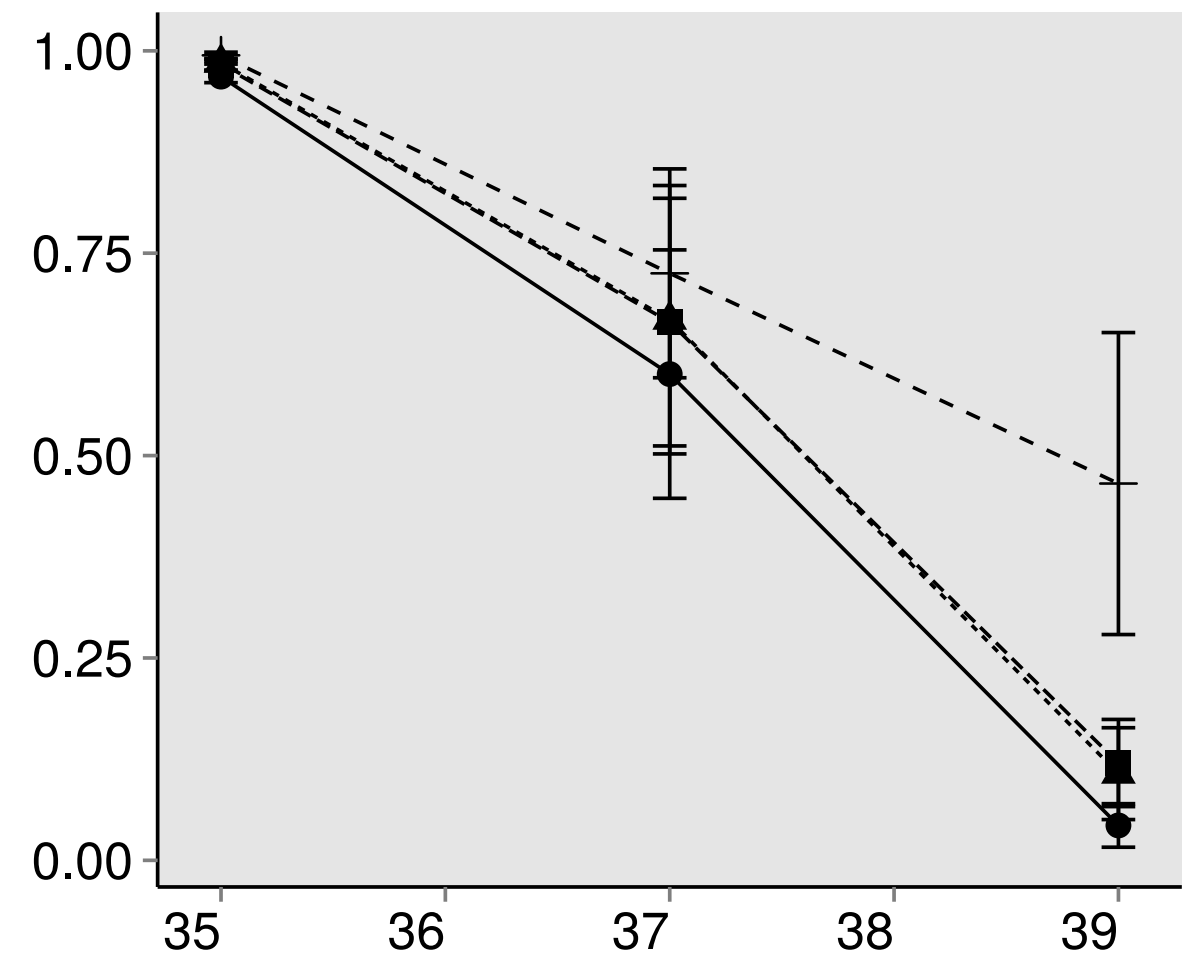

H. zealandica LLT
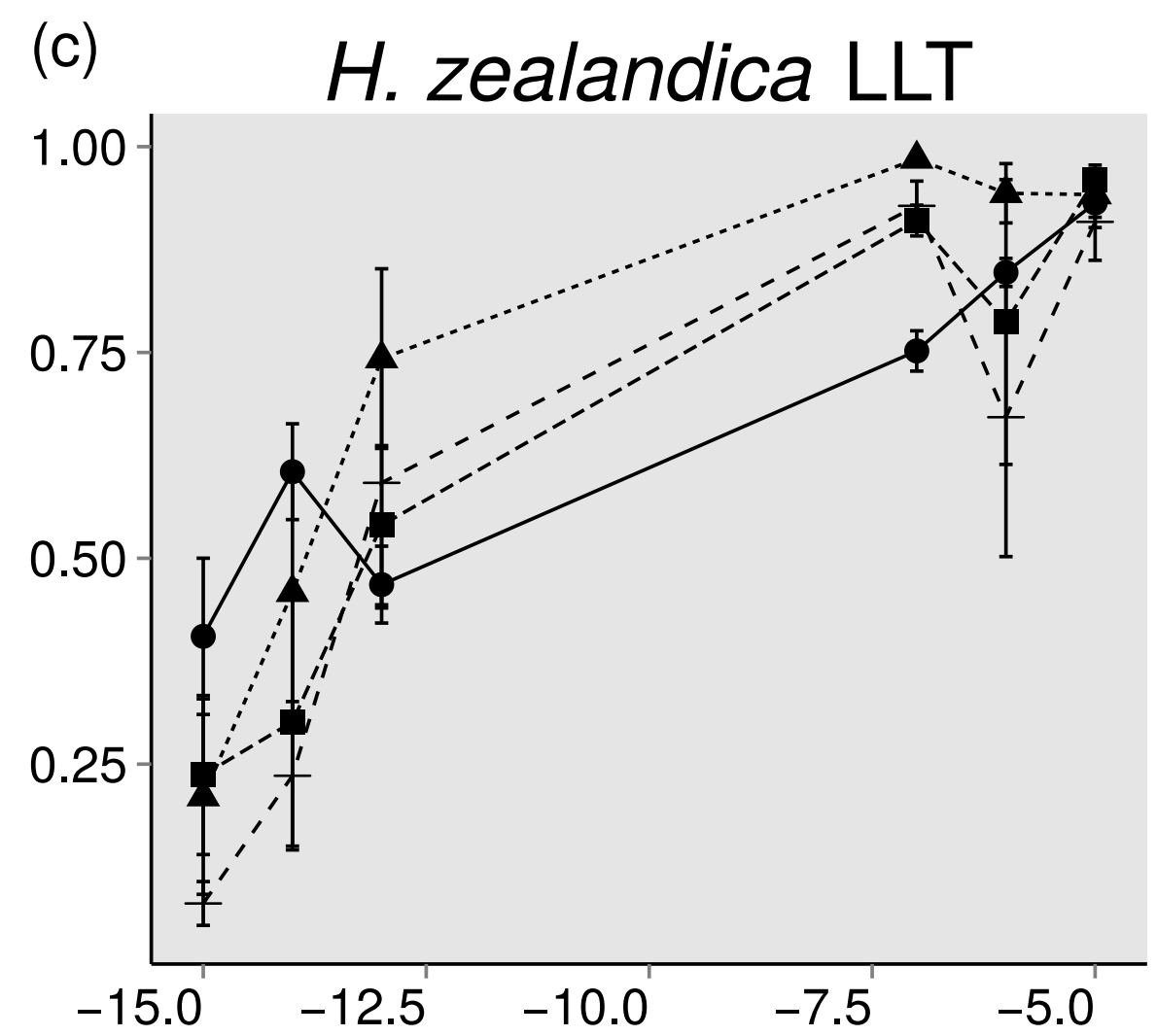

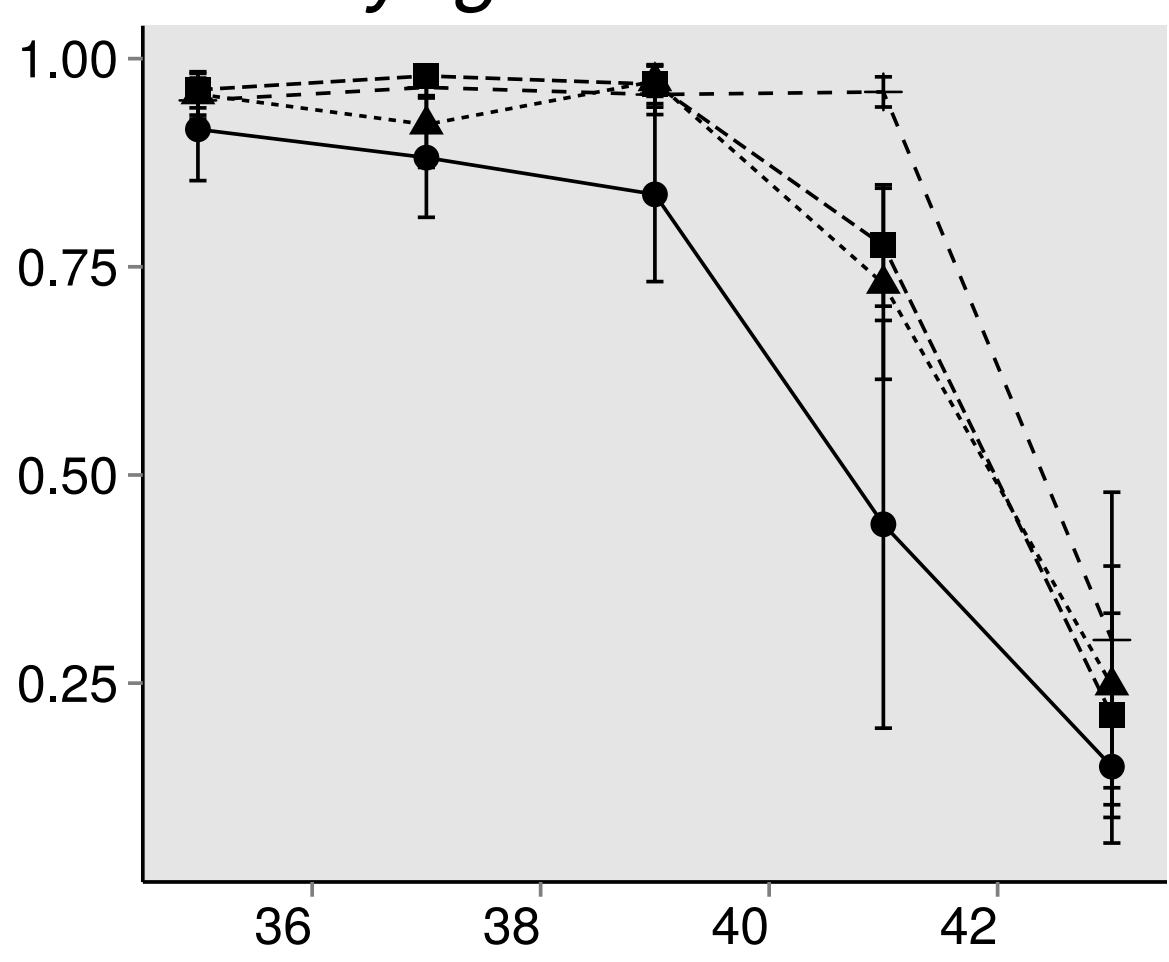

(d)

S. yirgalemense LLT

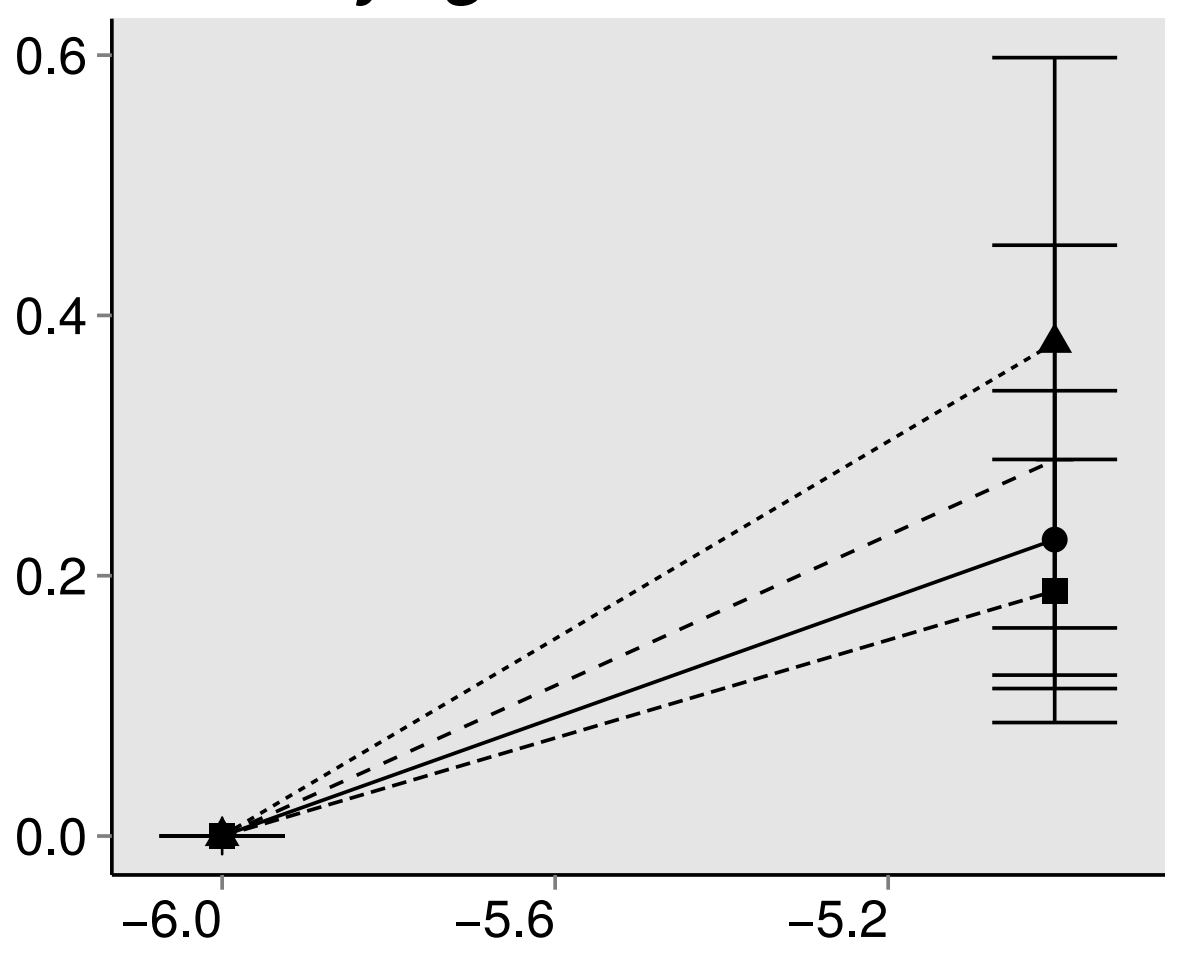

Temperature $\left({ }^{\circ} \mathrm{C}\right)$ 
Table $\mathbf{1}$ (on next page)

Generalised Linear Model summary for the effect of temperature on upper (ULT) and lower lethal temperature (LLT) limits of Heterorhabditis zealandica and Steinernema yirgalemense.

${ }^{a}$ residual deviance $=45.51, \mathrm{df}=60^{\mathrm{b}}$ residual deviance $=52.66, \mathrm{df}=48^{\mathrm{c}}$ residual deviance $=31.26, \mathrm{df}=35^{d}$ residual deviance $=23.76, \mathrm{df}=38$ 


\section{PeerJ Reviewing Manuscript}

\section{Effect}

LLT

$\begin{array}{llllll}\text { H. zealandica } & \\ & \text { Intercept } & 1 & 4.94 & 0.58 & 8.58<0.001 \\ & \text { Temperature } & 1 & 0.51 & 0.64 & 7.94<0.001 \\ \text { S. } \text { yirgalemense }^{b} & \text { Intercept } & 1 & 4.35 & 0.75 & 5.81<0.001 \\ & \text { Temperature } & 1 & 2.25 & 0.34 & 6.56<0.001\end{array}$

ULT

$\begin{array}{cc}\text { H. zealandica } & \text { Intercept } \\ & \text { Temperature } \\ \text { S. } \text { yirgalemense }^{d} & \text { Intercept } \\ \text { Temperature } \\ \text { dual deviance }=45.51, \mathrm{df}=60 \\ \text { dual deviance }=52.66, \mathrm{df}=48 \\ \text { dual deviance }=31.26, \mathrm{df}=35 \\ \text { dual deviance }=23.76, \mathrm{df}=38\end{array}$

${ }^{a}$ residual deviance $=45.51, \mathrm{df}=60$

${ }^{b}$ residual deviance $=52.66, \mathrm{df}=48$

${ }^{c}$ residual deviance $=31.26, \mathrm{df}=35$

${ }^{d}$ residual deviance $=23.76, \mathrm{df}=38$ df Estimate SE

151.13

6.65

$7.69<0.001$

$1 \quad-1.39$

0.18

$-7.7<0.001$

$1 \quad 37.22$

8.02

$4.64<0.001$

$1-0.91$

0.2

$-4.63<0.001$ 
Table 2 (on next page)

Generalised Linear Model / logit model predictions for 10, 50 and 90\% survival of the population (i.e. $\mathrm{LT}_{90}, \mathrm{LT}_{50}, \mathrm{LT}_{10}$ ) of Heterorhabditis zealandica and Steinernema yirgalemense at upper and lower temperatures. 


\section{PeerJ Reviewing Manuscript}

Upper Lethal

Temperatures $\left({ }^{\circ} \mathrm{C}\right)$

\begin{tabular}{r|c|r|r|rl|}
\multicolumn{3}{|c|}{ H. zealandica } & \multicolumn{3}{|c}{ S. yirgalemense } \\
\% & LT & \multicolumn{1}{|c|}{ SE } & \multicolumn{1}{l|}{ LT } & SE & \\
Survival & & & & & \\
10 & 38.2 & 0.3 & 43.2 & 0.7 \\
50 & 36.7 & 0.2 & 40.8 & 0.3 \\
90 & 35.1 & 0.2 & 38.4 & 0.6
\end{tabular}

\section{Lower Lethal}

\section{Temperatures $\left({ }^{\circ} \mathrm{C}\right)$}

\begin{tabular}{|c|c|c|c|c|}
\hline & \multicolumn{2}{|c|}{ H. zealandica } & \multicolumn{2}{|c|}{ S. yirgalemense } \\
\hline $\begin{array}{r}\% \\
\text { Survival }\end{array}$ & LT & SE & LT & SE \\
\hline 10 & -14.0 & 0.8 & -3.3 & 0.1 \\
\hline 50 & -9.7 & 0.3 & -2.4 & 0.0 \\
\hline 90 & -5.4 & 0.5 & -1.6 & 0.1 \\
\hline
\end{tabular}


Table 3 (on next page)

Wald's $\chi^{2}$ test with categorical acclimation and set temperature variables for both Lower Lethal Temperature (LLT) and Upper Lethal Temperature (ULT).

The generalized linear model used a binomial distribution for survival data with a logit link function and deviance was rescaled to 1 . Test not possible to be performed on $S$. yirgalemense LLT data. 


\section{PeerJ Reviewing Manuscript}

$\underline{\text { ULT }}$

H. zealandica

Temp

$\begin{array}{rrrr}X^{2} & \text { df } & & \text { P r } \\ 15.0 & & 2 & <0.001 \\ 0.34 & 3 & 0.95 \\ 4.5 & & 6 & 0.61\end{array}$

Acclimation x Temp

S. yirgalemense

\begin{tabular}{lrrrr} 
& \multicolumn{2}{c}{ df } & \multicolumn{2}{c}{$\mathrm{P}$} \\
Temp & 26.1 & 4 & $<0.001$ \\
Acclimation & 0.51 & 3 & 0.92 \\
Acclimation x Temp & 4.8 & & 11 & 0.94
\end{tabular}

\section{LLT}

H. zealandica

Temp

$x^{2} \quad \mathrm{df}$

$\mathrm{P}$

$\begin{array}{lll}42.9 & 6 & <0.001\end{array}$

Acclimation

$\begin{array}{lll}6.8 & 3 & 0.08\end{array}$

Acclimation x Temp

23.0

15

0.08 